\title{
Study on Hot Deformation Behavior of High Strength Construction Steel 34CrNiMo6
}

\author{
Feng Kang ${ }^{1}$, Echuan $\mathrm{Yang}^{2}$, Jun $\mathrm{Lin}^{1}$, and Chuankai $\mathrm{Hu}^{1}$ \\ ${ }^{1}$ Southwest Technology and Engineering Research Institute, Chongqing 400039, China \\ ${ }^{2}$ Chongqing University of technology, Chongqing 400054, China
}

\begin{abstract}
The hot pressure deformation tests were carried out by using Gleeble-2000 simulator at the temperature of $950{ }^{\circ} \mathrm{C} \sim 1150{ }^{\circ} \mathrm{C}$ and strain rate of $0.001 \mathrm{~s}^{-1} \sim 1 \mathrm{~s}^{-1}$ for a kind of high strength construction steel $34 \mathrm{CrNiMo6}$ for Crankshafts and the curve of its flow stress were obtained. By studied the data, the flow stress constitutive equation, hot deforming active energy and the $Z$ parameter were obtained. The curve of flow stress of $34 \mathrm{CrNiMo6}$ steel indicated that the flow stress was increased with the decrease of temperature or increase of the strain rate. During the deformation, temperature and strain rate take important effect on dynamic recrystallization and dynamic recovery. It was propitious to dynamic recrystallization with raising temperature or reducing strain rate, and also made for the refinement of grain.
\end{abstract}

\section{Introduction}

34CrNiMo6 steel is the high-strength structural steel. It is the material meeting the German standards, and it is the hardened and tempered steel. It has good comprehensive mechanical properties, which can be widely used in manufacturing the bearing parts with large section and complex shape, such as the bent axle of motor, connecting rod and cam etc. A factory now uses such material to manufacture the bent axle of motor after all-fiber forging. As its thermoplastic deformation behavior affects the product quality (usability and performance) directly, thus it is very important to decide the reasonable thermal deformation parameters for improving the material organization and performance. However, the existing research on such material mainly focuses on the thermal deformation process parameters and heat treatment process etc, the report about researched on thermal deformation behaviors of such material is rare ${ }^{[1-3]}$, therefore, in this thesis, the hot compression simulation test is adopted in the research of thermal deformation behaviors of 34CrNiMo6 steel so as to provide the experimental theory for developing plastic processing technology and improving the material organization performance.

\footnotetext{
* Corresponding author: tiannakaff@163.com
} 


\section{Test methods}

The 34CrNiMo6 material for test is taken from the $\$ 150 \mathrm{~mm}$ annealed forging material; the chemical composition is shown in Tab.1. The diameter of the sample is $\phi 10 \mathrm{~mm}$.

Table 1. Chemical composition of 34CrNiMo6 steel in wt $\%$

\begin{tabular}{|c|c|c|c|c|c|c|c|}
\hline $\mathrm{C}$ & $\mathrm{Cr}$ & $\mathrm{Ni}$ & $\mathrm{Mo}$ & $\mathrm{Mn}$ & $\mathrm{Si}$ & $\mathrm{P}$ & $\mathrm{S}$ \\
\hline 0.37 & 1.44 & 1.37 & 0.25 & 0.66 & 0.26 & 0.015 & 0.012 \\
\hline
\end{tabular}

The test is conducted on the thermal simulated test machine of Gleeble-2000 type. The argon is adopted as the protective gas to reduce the oxidation in deformation, and the graphite is filled as the lubricant in both ends of the sample to achieve the nearly uniform deformation of the sample. At first, the sample is heated to $1200{ }^{\circ} \mathrm{C}$ with heat preservation of $5 \mathrm{~min}$, and then cooled to the test temperature in the speed of $5^{\circ} \mathrm{C} / \mathrm{s}$ with heat preservation of $20 \mathrm{~s}$, and the temperature gradient generated in the temperature changing process is eliminated. The deformation temperatures of this compression test shall be: $950^{\circ} \mathrm{C}, 1000^{\circ} \mathrm{C}$, $1050^{\circ} \mathrm{C}, 1100^{\circ} \mathrm{C}$ and $1150^{\circ} \mathrm{C}$; the deformation rates shall be: $1 \mathrm{~S}^{-1}, 0.1 \mathrm{~S}^{-1}, 0.01 \mathrm{~S}^{-1}$ and 0.001 $\mathrm{S}^{-1}$. The maximum true strain is 0.9 .

\section{Stress-strain analyses}

Fig. 1 is the stress-strain curve under the test conditions of $34 \mathrm{CrNiMo6}$ steel. According to the figure, the flow stress is increased with the decrease of deformation temperature and the increase of strain rate. Because under the same strain rate, when the temperature is increased, the dynamic softening speed is increased, and if the softening degree is enlarged, the peak stress and steady flow stress shall be decreased; however, when the deformation temperatures are the same and the strain rate is increased, then the rate of work hardening shall be increased as well, and the peak stress and steady flow stress shall be increased correspondingly. When the strain rate is low, obvious peak occurs in the curve (Fig.2a,b), which is presented as dynamic recrystallization type curve; and when the strain rate is $0.1 \mathrm{~S}^{-}$ 1 , the peak value (Fig. 2c) only occurs in the curve when the temperature increases to 1050 ${ }^{\circ} \mathrm{C}$ or above, and dynamic recrystallization occurs. When the temperature is lower than $1050{ }^{\circ} \mathrm{C}$, the deformation process only has dynamic response; when the strain rate is increased to $1 \mathrm{~S}^{-1}$, no obvious peak value in curve under all temperatures (Fig. 2d), and only dynamic response occurs in the deformation process, which is presented as dynamic response curve. Therefore, in the deformation process of such material, the higher the temperature is, the lower the strain rate shall be, and it is good for dynamic recrystallization, so that the grain refinement of material, organization and performance can be improved.

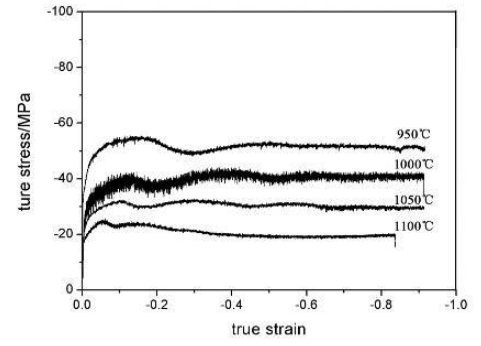

a. $\dot{\varepsilon}=0.001 S^{-1}$

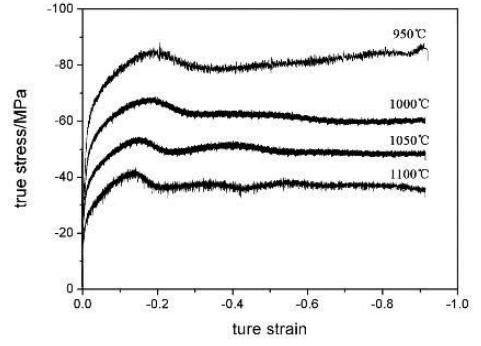

b. $\dot{\varepsilon}=0.01 S^{-1}$ 


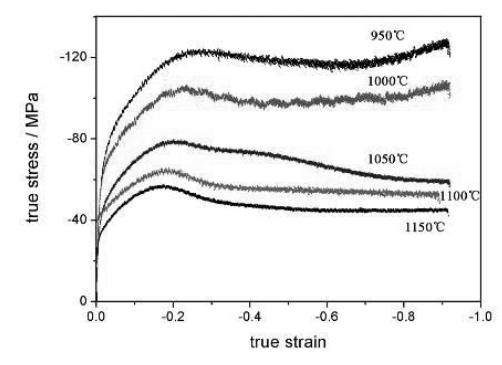

c. $\dot{\varepsilon}=0.1 S^{-1}$

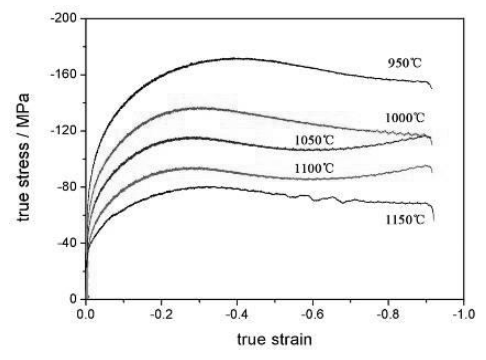

d. $\dot{\varepsilon}=1 S^{-1}$

Fig. 1. The stress- strain curves of $34 \mathrm{CrNiMo6}$ steel

According to relevant researches, the flow stress of the material is not only connected to the chemical components, but also related to parameters such as strain rate and deformation etc. According to researches on different hot working parameters, the following function relationship ${ }^{[4-5]}$ exists between the flow stress and the deformation conditions:

$$
\dot{\varepsilon}=A[\sinh (\alpha \sigma)]^{n} \exp \left(-\frac{Q}{R T}\right)
$$

Where, $\dot{\varepsilon}$ is the deformation rate, $\sigma$ is the peak stress or steady-state flow stress (the peak stress in this paper), $\mathrm{Q}$ is the deformation activation energy (reflect the complexity of thermal deformation), $\mathrm{A}, \mathrm{R}$ and $\mathrm{n}$ are the constants, and $\mathrm{T}$ is the deformation temperature.

Where, when the stress is low $(\alpha \sigma \leq 0.8), \sinh (\alpha \sigma) n$ in the equation (1) can be simplified into $\sigma \mathrm{n}$. When the stress is high $(\alpha \sigma>1.2), \sinh (\alpha \sigma) \mathrm{n}$ in the equation (1) can be simplified into $\exp (\beta \sigma)$; where $\alpha=\beta / \mathrm{n}, \mathrm{n}$ and $\beta$ are constants ${ }^{[6,7]}$.

During the high-temperature deformation process of the metal, to indicate the influence of deformation temperature and stress rate on the thermal deformation process, the ZenerHollomon parameter ${ }^{[8]}$ is introduced (the stress rate factor with temperature compensation: Z parameter):

$$
\mathrm{Z}=\dot{\varepsilon} \exp (Q / R T)
$$

Substitute two simplified methods in equation (1) into (1), we can know that:

$$
\begin{aligned}
& \dot{\varepsilon}=A \sigma^{n} \exp (-Q / R T) \\
& \dot{\varepsilon}=A \exp (\beta \sigma) \exp (-Q / R T)
\end{aligned}
$$

Take the logarithm in both sides of equation (3) and (4):

$$
\begin{gathered}
\ln \dot{\varepsilon}=\ln A+n \ln \sigma-Q / R T \\
\ln \dot{\varepsilon}=\ln A+\beta \sigma-Q / R T
\end{gathered}
$$

Under given temperature: seek the partial derivative on $\ln \dot{\varepsilon}$ in (5) and (6) separately, then:

$$
\begin{aligned}
& n=\left[\frac{\partial(\ln \dot{\varepsilon})}{\partial \ln \sigma}\right]_{T} \\
& \beta=\left[\frac{\partial(\ln \dot{\varepsilon})}{\partial \sigma}\right]_{T}
\end{aligned}
$$

Plotting the data obtained from thermal simulation compression test according to equation (7) and (8), which is as shown in Fig.2: 


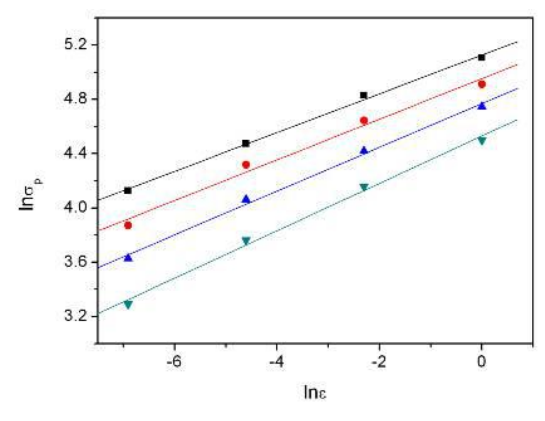

a. $\ln \sigma_{p}-\ln \dot{\varepsilon}$

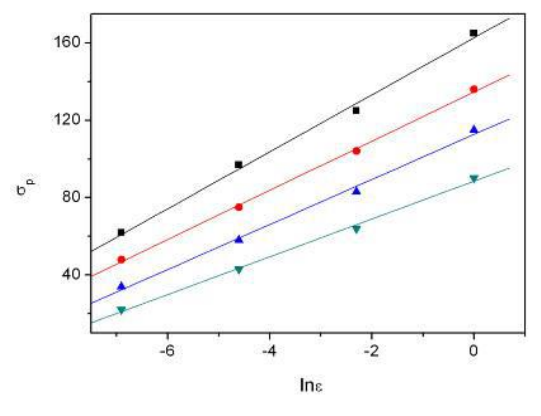

b. $\sigma_{p}-\ln \dot{\varepsilon}$

Fig.2. Relationship between peak stress and strain rate

According to the figure, both $\ln \sigma_{p}-\ln \dot{\varepsilon}$ and $\sigma_{p}-\ln \dot{\varepsilon}$ indicate obvious and approximate linear relationship, and implement the regression analysis with least square method; it gets $\mathrm{n}=6.36102, \beta=0.08202$ and $\alpha=\beta / \mathrm{n}=0.012894$.

Take the logarithm in both sides of equation (1):

$$
\ln \dot{\varepsilon}=\ln A+n \ln \sinh (\alpha \sigma)-Q / R T
$$

When $\dot{\varepsilon}$ is constant, seek the partial derivative on $1 / \mathrm{T}$ in equation (5), we can know that:

$$
Q=R n\left[\frac{\partial \ln \sinh (\alpha \sigma)}{\partial(1 / T)}\right]_{\dot{\varepsilon}}
$$

When $\mathrm{T}$ is constant, seek the partial derivative on $\dot{\varepsilon}$ in equation (9), we can know that:

$$
1 / n=\left[\frac{\partial \ln \sinh (\alpha \sigma)}{\partial \ln \dot{\varepsilon}}\right]_{T}
$$

According to equation (10) and (11), $\ln \sinh (\alpha \sigma)-\ln \dot{\varepsilon}$ and $\ln \sinh (\alpha \sigma)-1 / T$ can be all in linear relation; relation curve made according to test data is shown in Fig. 3 and Fig. 4:
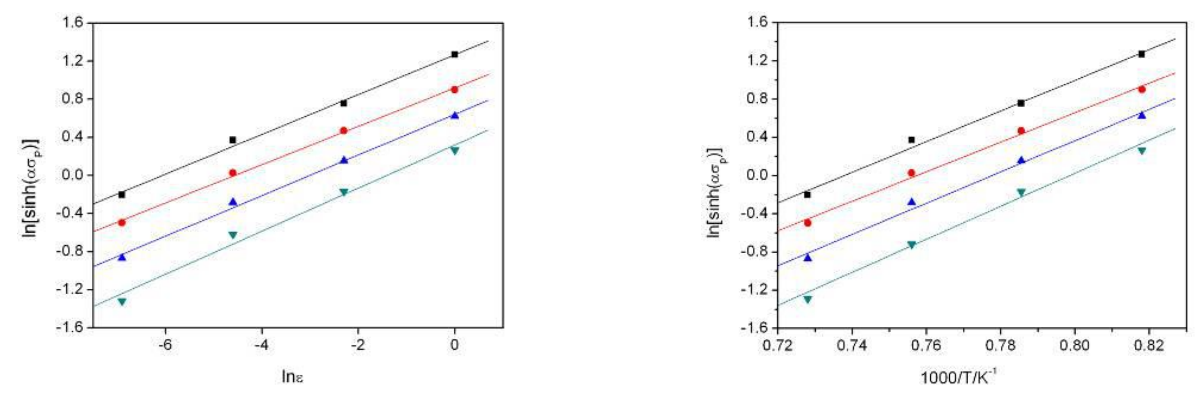

Fig. 3. Relationship between $\ln \sinh (\alpha \sigma)$ and $\ln \dot{\varepsilon}$ Fig. 4. Relationship between $\ln \sinh (\alpha \sigma)$ and $1 / \mathrm{T}$

Carry out linear regression analysis of Fig.3 and Fig.4; the obtained activation energy Q of hot deformation and other constant data are shown in Table 2:

Table 2. Parameters in hot deforming formulation

\begin{tabular}{|c|c|c|c|}
\hline $\mathrm{Q}, \mathrm{kJ} / \mathrm{mol}$ & $\mathrm{n}$ & $\alpha, \mathrm{MPa}$ & $\mathrm{R}, \mathrm{J} \cdot \mathrm{mol}^{-1} \mathrm{~K}^{-1}$ \\
\hline 636.936 & 4.7102 & 0.012894 & 8.31 \\
\hline
\end{tabular}


According to data in Table 2, parameter $Z$ can be expressed as: $Z=\dot{\varepsilon} \exp (636936 / 8.31 T)$

According to equation (1) and (2), there is:

$$
Z=A[\sinh (\alpha \sigma)]^{n}
$$

Take the logarithm of both sides, and get:

$$
\ln Z=\ln A+n \ln [\sinh (\alpha \sigma)]
$$

According to equation (13), $\ln Z$ and $\ln [\sinh (\alpha \sigma)]$ are in linear relation; Fig. 5 which is made based on test data is:

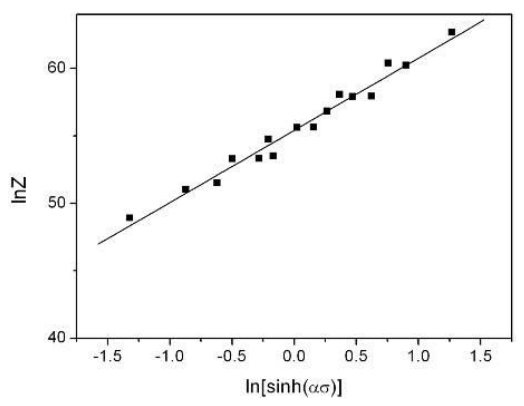

Fig. 5. Relationship between $\ln \sinh (\alpha \sigma)$ and $\ln Z$

From Fig.5 we can see, all data got from the test are near the regression straight line, which shows that the linear correlation is in high degree; the test data well reflected equation (12) that with the increase of deformation temperature and the decrease of strain rate, the parameter value of $\mathrm{Z}$ is decreasing, the peak stress is also decreasing, while dynamic recrystallization is also liable to come up. Calculate the intercept of this regression straight line, and $\ln A$ can be got, while constant $A=2.35 \times 1016$ in equation (13) can further be determined.

Take all data into equation (1), and get the flow stress constitutive equation of the steel:

$$
\dot{\varepsilon}=2.35 \times 10^{16}[\sinh (0.012 \sigma)]^{4.71} \exp \left(-\frac{636936}{R T}\right)
$$

\section{Summaries}

(1) Hot deformation activation energy Q of 34CrNiMo6 high-strength structural steel for this bent axle is $636.936 \mathrm{~kJ} / \mathrm{mol}$, and its hot deformation equation is $\dot{\varepsilon}=2.35 \times 10^{16}[\sinh (0.012 \sigma)]^{4.71} \exp \left(-\frac{636936}{R T}\right)$.

(2) Hot deformation activation energy Q of $34 \mathrm{CrNiMo6}$ steel is $636.936 \mathrm{~kJ} / \mathrm{mol}$, while $Z=\dot{\varepsilon} \exp (636936 / 8.31 T)$.

(3) During the deformation process, both the deformation temperature and strain rate play an important role in dynamic recrystallization and dynamic recovery of 34CrNiMo6 steel; while whether the increase of deformation temperature or decrease of strain rate is good for the appearance of dynamic recrystallization and grain refinement of deformed materials in the deformation process. 


\section{References}

1. J.L. Zhang, W.H. Zang, R.D Fu. et al. Hot deforming behaviors and microstructures of 2.25Cr-1Mo-0.25V steels[J]. Journal of plasticity engineering, 2010, 3 (17):44-48

2. B. Zhang, H.B. Zhang. Hot deformation behavior of $35 \mathrm{CrMo}$ steel[J]. Acta. Metallurgica Sinica, 2004, 40(10):1109-1114

3. M. Wang, H.P. Hong, X.M. Wang. Thermal deformation behavior and flow stress model of $37 \mathrm{Mn} 5$ steel[J]. Journal of Wuhan University of Science and Technology, 2010, 33(2):134-137

4. B. J. Zhang, G.P. Zhao, L.Y. Jiao. et al. Influence of hot working process on microstructures of superalloy GH4586[J]. Acta. Metallurgica Sinica, 2005, 41(4):351356

5. P.F. Liu, D. Liu, Z.J. Luo. et al. Flow behavior and dynamic recrystallization model for GH761 superalloy during hot deformation[J]. Rare Metal Materials and Engineering, 2009, 28(2):275-280

6. Jonas J J, Quelennec X, Jiang L. The Avrami kinetics of dynamic recrystallization[J].Acta materialia, 2009,57:2748-2756

7. C.X. Wang, X.M. Liu, Z.L. Tian. et al. Hot Deformation Behavior of 23Co14Ni12Cr3MoE Ultra-High Strength Steel[J]. Journal of Aeronautical Materials, 2011, 31(6):19-22

8. Almagro J F, Llovet X, Heredia M A, et al. Soluble fraction of stabilizing elements in ferritic stainless steel[J]. Microchim Acta, 2008, 161(3/4):323-327 